\title{
Clinical Presentation and Outcome of Perioperative Myocardial Infarction in the Very Elderly Following Hip Fracture Surgery
}

\author{
Bhanu P. Gupta, MD*, Jeanne M. Huddleston, MD", ${ }^{1,5}$ Lisa L. Kirkland, MD¹, Paul M. Huddleston, MD³, \\ Dirk R. Larson, $\mathrm{MSc}^{4}$, Rachel E. Gullerud ${ }^{4}$, M. Caroline Burton, MD ${ }^{1}$, Charanjit S. Rihal, MD², R. Scott Wright, MD²
}

${ }^{1}$ Division of Hospital Internal Medicine, Department of Medicine, Mayo Clinic, Rochester, Minnesota; ${ }^{2}$ Division of Cardiology, Department of Medicine, Mayo Clinic, Rochester, Minnesota; ${ }^{3}$ Department of Orthopedic Surgery, Mayo Clinic, Rochester, Minnesota; ${ }^{4}$ Division of Biomedical Statistics and Informatics, Department of Health Sciences Research, Mayo Clinic, Rochester, Minnesota; ${ }^{5}$ Division of Health Care Policy and Research, Department of Health Sciences Research, Mayo Clinic, Rochester, Minnesota.

BACKGROUND: Patterns of clinical symptoms and outcomes of perioperative myocardial infarction (PMI) in elderly patients after hip fracture repair surgery are not well defined.

METHODS: A retrospective 1:2 case-control study in a cohort of 1212 elderly patients undergoing hip fracture surgery from 1988 to 2002 in Olmsted County, Minnesota.

RESULTS: The mean age was $85.3 \pm 7.4$ years; $76 \%$ female. PMI occurred in 167 (13.8\%) patients within 7 days, of which $153(92 \%)$ occurred in first 48 hours; $75 \%$ of patients were asymptomatic. Among patients with PMI, inhospital mortality was $14.4 \%, 30$-day mortality was 29 (17.4\%), and 1-year mortality was 66 (39.5\%). PMI was associated with a higher inpatient mortality rate (odds ratio
[OR], 15.1; confidence interval [Cl], 4.6-48.8), 30-day mortality (hazard ratio $[\mathrm{HR}], 4.3 ; \mathrm{Cl}, 2.1-8.9$ ), and 1-year mortality (HR, 1.9; Cl, 1.4-2.7).

CONCLUSION: Elderly patients, after hip fracture surgery, have a higher incidence of PMI and mortality than what guidelines indicate. The majority of elderly patients with PMI did not experience ischemic symptoms and required cardiac biomarkers for diagnosis. The results of our study support the measurement of troponin in postoperative elderly patients for the diagnosis of $\mathrm{PMI}$, in order to implement in-hospital preventive strategies to reduce PMI-associated mortality. Journal of Hospital Medicine 2012;7:713-716. (C) 2012 Society of Hospital Medicine
Perioperative myocardial infarction (PMI) often remains unrecognized with higher mortality in the aged. $^{1-3}$ Perioperative ischemic symptoms are often masked by analgesia, sedation, and transient and subtle electrocardiographic (ECG) changes. Postoperative troponin measurement is not routinely done for PMI diagnosis. Hip fracture surgery is the most common non-cardiac surgical procedure in the elderly, with limited data on clinical presentation of PMI. ${ }^{4-6}$ Moreover, the elderly are significantly underrepresented in clinical studies. ${ }^{7}$ We therefore examined the clinical presentation of PMI and its outcomes among elderly patients admitted for hip fracture repair.

\section{METHODS}

\section{Study Population}

A population-based, retrospective, case-control study was conducted of all residents in Olmsted County, Minnesota undergoing surgery for hip fracture repair from January 1, 1988 through December 31, 2002.

\footnotetext{
*Address for correspondence and reprint requests: Bhanu P. Gupta, MD, Division of Hospital Internal Medicine, Department of Medicine, Mayo Clinic, 200 First St, Rochester, MN 55905; Telephone: 507-255-8715; Fax: 507-284-0164; E-mail: gupta.bhanu@mayo.edu

Additional Supporting Information may be found in the online version of this article.

Received: December 2, 2011; Revised: July 4, 2012; Accepted: July 5, 2012

2012 Society of Hospital Medicine DOI 10.1002/jhm.1967

Published online in Wiley Online Library (Wileyonlinelibrary.com).
}

Primary indication for the surgery was proximal femur (femoral neck or subtrochanteric) fracture. Patients who were $<65$ years old, had a pathological hip fracture, multiple injuries or fractures, surgery $>72$ hours after injury (due to higher mortality with delayed surgery), ${ }^{8}$ nonsurgical management of hip fracture repair, or incomplete data were excluded. All patients provided prior authorization to use their medical records for research, per institutional protocols. ${ }^{9}$

\section{Criteria for Perioperative Myocardial Infarction and Death}

We utilized the universal definition of acute myocardial infarction ${ }^{10}$ to define PMI within the first 7 days following hip fracture surgery. We included creatine kinase-MB fraction (CK-MB) as the biomarker for 1988-July 2000, and troponin as the biomarker for August 2000-2002. Mortality was defined as death from any cause within the first year following hip fracture repair. Deaths were identified through the National Death Index.

\section{Statistical Analysis}

For each case of PMI, we identified 2 control patients who were selected at random from the non-PMI patient population. These controls were matched to cases based on age at the time of surgery ( \pm 5 years) and gender in 1:2 ratios. Baseline characteristics across PMI and non-PMI groups were compared using the Kruskal-Wallis test (for continuous data) and the chi-square or Fisher's exact tests (for categorical 


\begin{tabular}{|c|c|c|c|}
\hline Characteristics, $\mathrm{n}(\%)$ & $\begin{array}{l}\text { Patients } \\
\text { With PMl } \\
(\mathrm{N}=167)\end{array}$ & $\begin{array}{c}\text { Patients } \\
\text { Without PMI } \\
(\mathrm{N}=334)\end{array}$ & $P$ Value $^{*}$ \\
\hline Age mean $\pm S D$ & $85.3 \pm 7.4$ & $85.2 \pm 7.1$ & 0.5 \\
\hline Weight $(\mathrm{kg})$ mean \pm SD & $59.98 \pm 16.7$ & $59.80 \pm 13.9$ & 0.5 \\
\hline Women & $127(76.4)$ & $254(76)$ & 0.5 \\
\hline \multicolumn{4}{|l|}{ Any symptom of ischemia, n (\%) } \\
\hline Chestarm pain & $11(7)$ & $4(1)$ & 0.002 \\
\hline Dyspnea & 20 (12) & $14(4)$ & 0.001 \\
\hline Nausea/vomiting & $8(5)$ & $6(2)$ & 0.08 \\
\hline Diaphoresis & $1(1)$ & $1(0.3)$ & 1.0 \\
\hline PND & $3(2)$ & $1(0.3)$ & 0.3 \\
\hline \multicolumn{4}{|l|}{ ECG changes, $n(\%)$} \\
\hline ST-segment elevation MI & $12(7.2)$ & 0 & 0.01 \\
\hline $\begin{array}{l}\text { New ECG changes consistent } \\
\text { with ischemia }\end{array}$ & $38(22.8)$ & $1(0.3)$ & 0.01 \\
\hline \multicolumn{4}{|c|}{ Biochemical evidence of ischemia, n (\%) } \\
\hline CK-MB十 & $147(88)$ & $20(6)$ & \pm 0.01 \\
\hline Troponinf & $52(33)$ & $9(3)$ & \pm 0.001 \\
\hline \multicolumn{4}{|l|}{ Laboratory markers } \\
\hline Hemoglobin gm/dL mean (SD) & $8.9 \pm 1.0$ & $9.4 \pm 1.2$ & \pm 0.001 \\
\hline $\begin{array}{l}\text { Postoperative anemia } \\
\quad(<8.0 \mathrm{gm} / \mathrm{dL}), \mathrm{n}(\%)\end{array}$ & $22(13.2)$ & $37(11.1)$ & 0.5 \\
\hline Length of stay (days), mean $\pm S D$ & $11.6 \pm 7.7$ & $7.4 \pm 6.4$ & \pm 0.001 \\
\hline In-hospital outcome & & & $<0.001$ \\
\hline Dead & $24(14.4)$ & $4(1.2)$ & \\
\hline Alive & $143(85.6)$ & $330(98.8)$ & \\
\hline 30-Day outcome & & & $<0.001$ \\
\hline Dead & $29(17.4)$ & $14(4.2)$ & \\
\hline Alive & $138(82.6)$ & $320(95.8)$ & \\
\hline 1-Year outcome & & & $<0.001$ \\
\hline Dead & $66(39.5)$ & $77(23)$ & \\
\hline Alive & $101(60.4)$ & $257(77)$ & \\
\hline
\end{tabular}

Abbreviations: CK-MB, creatine kinase-MB fraction; ECG, electrocardiogram; Ml, myocardial infarction; PMl, perioperative myocardial infarction; PND, paroxysmal nocturnal dyspnea; SD, standard deviation. *Univariate analysis, $P$ values for those with PMI vs without PMl. †Ml reference value $>5.0 \mathrm{ng} / \mathrm{ml}$. $\ddagger$ Ml reference value $>0.01 \mathrm{ng} / \mathrm{ml}$.

data). Mean values were utilized in place of the missing values for the following variables: preoperative troponin (missing values $88 \quad[17.5 \%]$ ), CK-MB (8 $[1.6 \%])$, troponin $(21[5.4 \%])$, and postoperative hemoglobin (17 [3.4\%]). Univariate predictors of PMI with $P \leq 0.2$ baseline characteristics were entered into a multivariate, conditional, logistic regression analysis. Rates of outcomes were calculated using the KaplanMeier method, and by a landmark survival curve for those with and without PMI. Cox proportional hazards analysis was utilized for survival analysis at 30 days and 1 year. All statistical tests were 2 -sided, and $P$ values $<0.05$ were considered significant. All analyses were performed using SAS for UNIX (version 9.1.3; SAS Institute, Inc, Cary, NC).

\section{RESULTS}

In the cohort of 1212 with hip fracture surgeries, 167 $(13.8 \%)$ cases of PMI occurred in the first 7 days, of which 153 (92\%) occurred within the first 48 hours. A total of 334 controls were matched with 167 cases of PMI. Table 1 summarizes the demographic characteristics of the study participants. Of the patients with PMI, 25.2\% experienced symptoms of ischemia; $7 \%$
TABLE 2. Multivariate and Survival Analysis of Risk Factors for Perioperative Myocardial Infarction, In-Hospital, 30-Day, and 1-Year Mortality

\begin{tabular}{lccc}
\hline & $\begin{array}{c}\text { Unadjusted OR } \\
(95 \% \mathrm{Cl})\end{array}$ & $\begin{array}{c}\text { Adjusted OR } \\
(95 \% \mathrm{Cl})\end{array}$ & P Value \\
\hline $\begin{array}{l}\text { Perioperative myocardial infarction } \\
\text { Coronary artery disease }\end{array}$ & $3.0(2.1-4.5)$ & $3.5(2.2-5.6)$ & $<0.001$ \\
$\quad$ Serum creatinine $>2.0 \mathrm{mg} / \mathrm{dL}$ & $2.7(1.6-4.8)$ & $2.4(1.3-4.4)$ & 0.003 \\
In-hospital mortality & & & \\
Age 85-89 & $1.7(0.8-3.7)$ & $5.3(1.6-17.7)$ & 0.01 \\
Age $\geq 90$ & $2.2(1.0-4.8)$ & $8.9(2.6-30.8)$ & $<0.001$ \\
Male gender & $3.0(1.4-6.4)$ & $5.8(2.2-15.2)$ & $<0.001$ \\
Postoperative anemia (<8.0 gm/dL) & $4.2(1.7-10.0)$ & $3.5(1.2-9.9)$ & 0.02 \\
Perioperative myocardial infarction & $14.0(5.2-48.0)$ & $15.1(4.6-49.0)$ & $<0.001$ \\
30-Day mortality & & & \\
$\quad$ Perioperative myocardial infarction & $4.1(2.2-7.8)$ & $4.3(2.1-8.9)$ & $<0.001$ \\
1-Year mortality & & & \\
Age 85-89 & $1.3(0.8-1.9)$ & $1.6(1.0-2.4)$ & $<0.03$ \\
Age $\geq 90$ & $1.9(1.3-2.9)$ & $2.0(1.4-3.1)$ & 0.001 \\
Male gender & $1.9(1.3-2.6)$ & $2.1(1.5-3.0)$ & $<0.001$ \\
Dementia & $2.5(1.8-3.6)$ & $2.7(1.9-3.8)$ & $<0.001$ \\
Perioperative myocardial infarction & $2.0(1.5-2.8)$ & $1.9(1.4-2.7)$ & 0.001 \\
\hline
\end{tabular}

NOTE: Risk factors adjusted for both logistic regression analysis and Cox proportional hazard ratio: Age $>70$ years in 5-year increments, male gender, hypertension, coronary artery disease, congestive heart failure, diabetes mellitus, cerebrovascular disease, chronic obstructive pulmonary disease, dementia, preoperative and postoperative aspirin, beta-blocker, angiotensin receptor blockers. Abbreviations: $\mathrm{Cl}$, confidence interval; OR, odds ratio.

reported chest pain, and $12 \%$ reported dyspnea. Only $22.8 \%$ of patients with PMI had ECG changes consistent with ischemia. ST elevation MI was present in $7.2 \%$ patients. PMI patients had a lower mean hemoglobin compared to the patients without PMI $(8.9 \mathrm{mg} /$ $\mathrm{dL}$ vs $9.4 \mathrm{mg} / \mathrm{dL}, P<0.001)$. Median length of stay (LOS) in the hospital was higher among patients who experienced PMI (11.6 vs 7.4 days, $P<0.001$ ). Overall in-hospital mortality was $5.6 \%$. There were 24 deaths $(14.4 \%)$ in the PMI group compared to 4 $(1.2 \%)$ in-hospital deaths in patients without PMI $(P<0.001)$. A total of $473(94 \%)$ patients survived to discharge. At 30-day follow-up, there were 29 $(17.4 \%)$ deaths in the PMI group and $14(4.2 \%)$ deaths in non-PMI group. During the follow-up for 1 year, there were $143(29 \%)$ deaths: PMI 66 (39.5\%) and $77(23 \%)$ non-PMI group $(P<0.01)$.

Table 2 describes the risk factors associated with PMI in-hospital, 30-day, and 1-year mortality. Risk factors for PMI were coronary artery disease (CAD) (odds ratio $[\mathrm{OR}], 3.5$; confidence interval [CI], 2.2-5.6), and serum creatinine $>2 \mathrm{mg} / \mathrm{dL}$ (OR, 2.4; CI, 1.3-4.4). Risk factors for in-hospital mortality were age 85-89 (OR, 5.3; CI, 1.6-17.7), age $\geq 90$ (OR, 8.9; CI, 2.6-30.8), PMI (OR 15.1; CI, 4.6-48.8), male gender (OR 5.8; CI, 2.2-15.2), dyspnea (OR 5.4; CI, 1.8-16.9), and hemoglobin $<8.0$ $\mathrm{gm} / \mathrm{dL}$ (OR, 3.5; CI, 1.2-9.9). PMI was a strong predictor for 30-day mortality (hazard ratio [HR], 4.3; CI, 2.1-8.9). Risk factors for 1-year mortality were: age $\geq 90$ (HR, 2.0; CI, 1.4-3.1), male gender (HR, 2.1; CI, 1.5-3.0), and PMI (HR, 1.9; CI, 1.4-2.7). 


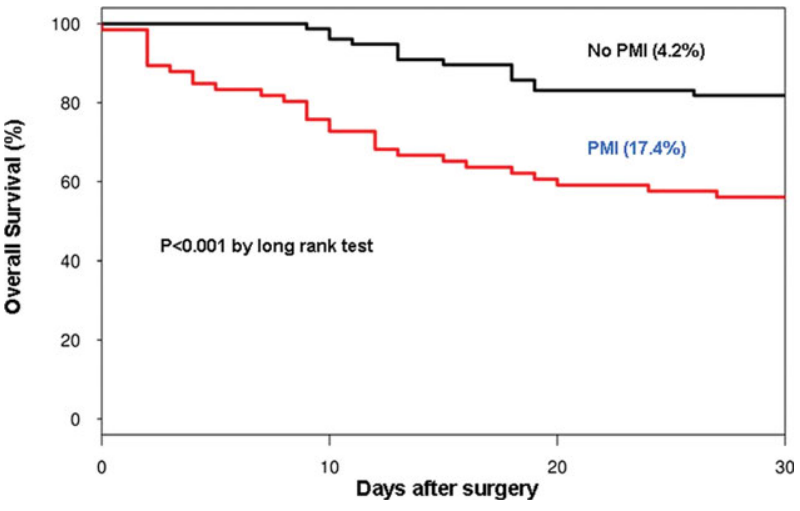

FIG. 1. Kaplan-Meier postoperative survival cure curve for 30-day survival for patients with and without perioperative myocardial infarction (PMI).

Figures 1 and 2 describe the Kaplan-Meier survival curves for patients with and without PMI.

\section{DISCUSSION}

We report the high incidence of PMI $(13.8 \%)$ in the cohort of 1212 elderly patients (mean age 85 years) undergoing hip fracture surgery. Most PMI events $(92 \%)$ occurred within the first 48 hours of surgery. Most of the events $(75 \%)$ were asymptomatic. Elderly patients with PMI had an increased hospital LOS by 4.2 days, with high in-hospital mortality $(13.8 \%), 30$ day mortality $(17.4 \%)$, and 1-year mortality $(39.5 \%)$.

Most of the PMI patients were identified with cardiac biomarkers on the basis of universal definition of MI within the first 48 hours. Although universal definition of MI does not define PMI as a separate type, PMI shares common pathophysiological pathways of Type 1 MI (primary coronary event) and Type 2 MI (myocardial oxygen supply-demand imbalance). Postoperative tachycardia, hemodynamic instability, anemia, and hypoxemia may initiate pathways causing more Type 2 MI. Our study highlights the continued need for active surveillance of clinical symptoms, postoperative ECG monitoring for ST-T changes, and utilizing cardiac troponin in older postoperative patients to improve diagnostic accuracy of PMI.

The current study has higher asymptomatic PMI events when compared to a study of Devereaux et al. ${ }^{11}$ The current study had an older population undergoing urgent hip fracture surgery, with a higher burden of CAD $(60 \%)$ and renal failure $(20 \%)$ with serum creatinine $>2 \mathrm{gm} / \mathrm{dL}$ (see Supporting Information, Appendix 1 , in the online version of this article). Older age and a higher burden of these risk factors may explain the higher incidence of PMI in the current study. Perioperative liberal use of analgesics in hip fracture surgery may explain more asymptomatic patients.

In light of the recently published FOCUS ${ }^{12}$ trial, an important finding from our study is that postoperative anemia among elderly $(<8.0 \mathrm{gm} / \mathrm{dL})$ is associated with a 3.5 -fold increased in-hospital mortality. It is critical to maintain perioperative hemoglobin above $8.0 \mathrm{gm} / \mathrm{dL}$

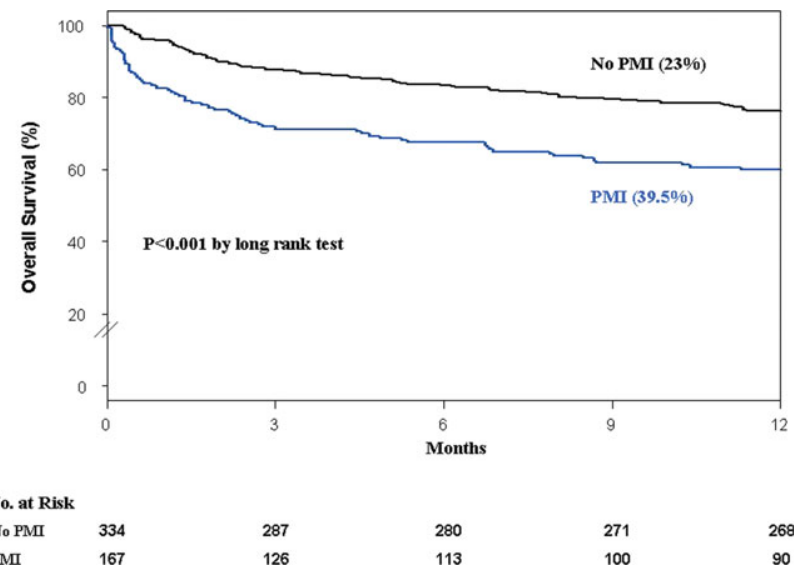

FIG. 2. Kaplan-Meier postoperative 1-year survival curves for patients with and without perioperative myocardial infarction (PMI).

in very elderly patients, due to asymptomatic presentation of PMI.

In the current study, PMI is associated with a 15fold increased risk of in-hospital death and a 4.3-fold increased risk of 30-day mortality in the elderly. Advanced age ( $\geq 85$ years) is a well known strong predictor of initial hospital admission and death in elderly patients after outpatient surgery. ${ }^{13}$ Furthermore, the odds for an in-hospital death increase by $70 \%$ for each 10-year increase in age. ${ }^{14}$ Therefore, early detection of silent PMI among at-risk elderly patients by cardiac biomarkers may help in optimization of cardiac pharmacotherapy known to decrease short- and long-term mortality.

There are limitations inherent to the retrospective design and methodology. Data collection was done through the year 2002. CK was used for the period that spans from 1988 to mid-2000. Troponin was used from 2000 to 2002. Statin use was not analyzed for lack of significant data. Limited use of beta-blockers $(15 \%)$ and angiotensin-converting-enzyme (ACE) inhibitors $(25 \%)$ may also contribute to higher events (see Supporting Information, Appendix 1, in the online version of this article).

\section{CONCLUSIONS}

Elderly patients have a higher incidence of PMI and mortality after hip fracture surgery than what guidelines indicate. The majority of the elderly patients with PMI did not experience ischemic symptoms and required cardiac biomarkers for diagnosis. The results of our study support the measurement of troponin in postoperative elderly patients for the diagnosis of PMI to implement in-hospital preventive strategies to reduce PMI-associated mortality.

\section{Acknowledgements}

The authors gratefully acknowledge the assistance of Ms Dawn Bergen in drafting and editing the manuscript.

Disclosures: This research was supported by funding from AHA grant 03-30103N-04, Rochester Epidemiology Project (grant RO1-AR30582 from the National Institute of Arthritis and Musculoskeletal and Skin Diseases). The project was also supported by the National Center for 
Research Resources and the National Center for Advancing Translational Sciences, National Institutes of Health, through grant UL1 RR024150. The content is solely the responsibility of the authors and does not necessarily represent the official views of the NIH.

\section{References}

1. Polanczyk CA, Marcantonio E, Goldman L, et al. Impact of age on perioperative complications and length of stay in patients undergoing noncardiac surgery. Ann Intern Med. 2001;134(8):637-643.

2. Haentjens P, Magaziner J, Colón-Emeric CS, et al. Meta-analysis: excess mortality after hip fracture among older women and men. Ann Intern Med. 2010;152(6):380-390.

3. Batsis JA, Huddleston JM, Melton LJ, et al. Body mass index (BMI) and risk of noncardiac postoperative medical complications in elderly hip fracture patients: a population-based study. J Hosp Med. 2009;4(8):E1-E9.

4. Melton LJIII. History of the Rochester Epidemiology Project. Mayo Clin Proc. 1996;71(3):266-274.

5. Brauer CA, Coca-Perraillon M, Cutler DM, Rosen AB. Incidence and mortality of hip fractures in the United States. JAMA. 2009;302(14): 1573-1579.

6. Batsis JA, Huddleston JM, Melton ILJ, et al. Body mass index and risk of adverse cardiac events in elderly patients with hip fracture: a population-based study. J Am Geriatr Soc. 2009;57(3):419-426.

7. Alexander KP, Newby LK, Cannon CP, et al. Acute coronary care in the elderly, part I. Non-ST-segment-elevation acute coronary syn- dromes: a scientific statement for healthcare professionals from the American Heart Association Council on Clinical Cardiology: in collaboration with the Society of Geriatric Cardiology. Circulation. 2007;115(19):2549-2569.

8. Mullen JO, Mullen NL. Hip fracture mortality. A prospective, multifactorial study to predict and minimize death risk. Clin Orthop Relat Res. 1992;280:214-222.

9. Gibbons RJ, Chatterjee K, Daley J, et al. ACC/AHA/ACP-ASIM guidelines for the management of patients with chronic stable angina. I Am Coll Cardiol. 1999;33(7):2092-2190.

10. Thygesen K, Alpert JS, White HD; for the Joint ESC/ACCF/AHA/ WHF Task Force for the Redefinition of Myocardial Infarction. Universal definition of myocardial infarction. J Am Coll Cardiol. 2007; 50(22):2173-2195.

11. Devereaux PJ, Xavier D, Pogue J, et al. Characteristics and shortterm prognosis of perioperative myocardial infarction in patients undergoing noncardiac surgery. Ann Intern Med. 2011;154(8): 523-528.

12. Carson JL, Terrin ML, Noveck H, et al. Liberal or restrictive transfusion in high-risk patients after hip surgery. N Engl J Med. 2011; 365(26):2453-2462.

13. Fleisher LA, Pasternak LR, Herbert R, Anderson GF. Inpatient hospital admission and death after outpatient surgery in elderly patients: importance of patient and system characteristics and location of care. Arch Surg. 2004;139(1):67-72.

14. Granger CB, Goldberg RJ, Dabbous O, et al. Predictors of hospital mortality in the global registry of acute coronary events. Arch Intern Med. 2003;163(19):2345-2353. 